\title{
Correspondence between waist-to-height ratio and body mass index in juniors
}

\author{
Andrew Yatsko* \\ ITMS, the University of Ballarat, VIC, Australia
}

Received: July 9, 2017

DOI: $10.5430 /$ jbei.v4n1p1
Accepted: October 22, $2017 \quad$ Online Published: October 30, 2017

URL: https://doi.org/10.5430/jbei.v4n1p1

\begin{abstract}
Despite the increase in body mass through childhood and adolescence is countered by the increase in height in the Body Mass Index (BMI), this measure is inadequate for judging the degree of excess weight among the young. Unlike using clearly defined cut points, same for any stage of adulthood, it is required to consult BMI-for-age charts, which can be a demanding exercise when data analysis is involved. The waist circumference to height ratio (WCHR) was hypothesised to be invariant to age change, and this is generally supported by the epidemiological evidence. This paper analyses a sample of NHANES data to find a connection between BMI, WCHR and Age. A strong linearity between the anthropometric measures is demonstrated, thus enabling estimation of WCHR for a given BMI and Age. The pattern of change of this parameter at BMI levels that indicate the transition to overweight state or obesity thus becomes unravelled. The results strongly support the feasibility of a universal WCHR threshold for the overweight state past early childhood and through adolescence, and the estimated one is similar to the WCHR levels found elsewhere in the literature.
\end{abstract}

Key Words: Body mass index, Waist circumference to height ratio, Childhood, Adolescence, Obesity, Cardiometabolic disorders, NHANES

\section{INTRODUCTION}

The industrial automation on a large scale brought about a drastic reduction in manual labour, including in agriculture. The sedentary lifestyle that had ensued, affordability and preference of deeply processed, easily digestible food are the main driving factors of the epidemic of obesity in developed countries as well as around the world. The obesity is responsible for a range of diseases regarded rare in the past. Children and adolescents are generally more active and have an uncompromised health potential in the face of challenges presented by various diseases. ${ }^{[1]}$ Therefore, susceptibility of this cohort of population to metabolic disorders was somewhat overlooked. ${ }^{[2,3]}$ Nowadays, it is widely recognised that even in youth the hypertension $(\mathrm{HT})^{[4]}$ and the type two diabetes (T2DM) can be contracted. ${ }^{[5]}$ Moreover, the current epidemiological research supports the understanding that obesity in adolescence, but not necessarily in childhood, is tracking into adulthood; and the same is true of markers indicating risk of the cardiovascular disease (CVD) and T2DM. ${ }^{[2,3]}$ The screen time and the fast food consumption are two major drivers of obesity in youth. ${ }^{[6,7]}$ Also, a low family income may restrict nutritional choices. ${ }^{[8]}$ Because of the lagging adolescent obesity, another wave of adulthood obesity, ${ }^{[9]}$ the epidemic that started to show some signs of abating, especially in developed countries, ${ }^{[10]}$ can be expected.

At the same time, the aforementioned socio-economic and physiological drivers are applied onto causes that predispose

*Correspondence: Andrew Yatsko; Email: balunyaan@gmail.com; Address: ITMS, the University of Ballarat, VIC 3353, Australia. 
to obesity. Studies involving twins estimate that $30 \%$ to $70 \%$ of obese have a genetic propensity to obesity, ${ }^{[11]}$ some ethnicities more vulnerable than others. ${ }^{[10]}$ There is also a clear link between the maternal obesity/weight gain at the time of pregnancy and subsequent obesity of the offspring. ${ }^{[12]} \mathrm{Con}$ versely, an under-nutrition on the part of mothers can also realise as childhood obesity in the offspring. ${ }^{[12]}$ This type of life conditioning is known as "fetal" programming, in contrast to the genetic programming. Similarly, an exposure to harsh environment or diet lacking nutrients in childhood can cause stunting/growth retardation, and otherwise the organism reprogramming towards a more economical phenotype, which later in life can exacerbate the consequences of being overweight. ${ }^{[13]}$ In this connection, at 5-7 years of age the organism normally reaches certain physiological maturity. Achieving this earlier was observed to lead to childhood obesity which also tracks into adulthood. Low weight at birth persons are especially affected. This has been argued to be caused by an imbalanced nutrition through the early childhood, specifically lack of fat in the diet, with preference given to proteins, particularly using low-fat milk instead of the whole milk. ${ }^{[14]}$

The prenatal life harbours certain perils which may present postnatally, and a miscalculated or a restricted nutrition in the early childhood has consequences for the main part of it; so, unless all those "turns" are successfully navigated, the proverbial ball becomes only bigger and little is left for the adolescence to deal with the problems. Of course, the genetic factors have a footprint on the entire life. However, the growth intensity and the diet variability provide a significant leverage over obesity in childhood years, and even in adolescence. Clearly, the obesity among young presents a number of challenges. Little is done to address them. The existing recipes apply mainly to adulthood. ${ }^{[15]}$

The body mass index (BMI) calculated as in Equation 1, accredited to Quetelet, is a standard measure of normality/excessiveness of the human body weight. ${ }^{[16]}$

$$
\operatorname{BMI}\left(\mathrm{kg} / \mathrm{m}^{2}\right)=\frac{\text { weight }(\mathrm{kg})}{[\text { height }(\mathrm{m})]^{2}}
$$

Adult persons are regarded overweight if their BMI is $25 \mathrm{~kg} / \mathrm{m}^{2}$ or more, and regarded obese if their BMI is $30 \mathrm{~kg} / \mathrm{m}^{2}$ or more. ${ }^{[15]}$ These thresholds are sometimes interpreted as cut-off levels triggering indication for treatment by one or other means. ${ }^{[15]}$ While there is a strong correlation of high BMI with various cardiometabolic disorders such as CVD, HT, and most notably T2DM, ${ }^{[2,4,5]}$ and increased mortality from these and other causes, ${ }^{[17]}$ these numbers are nothing more but a selected by consensus the origin $\left(25 \mathrm{~kg} / \mathrm{m}^{2}\right)$ and the unit of measure $\left(5 \mathrm{~kg} / \mathrm{m}^{2}\right)$ for the excessiveness of human body weight. Historically, the $5 \mathrm{~kg} / \mathrm{m}^{2}$ is approximately the standard deviation (SD) of BMI distribution in a large population, and $25 \mathrm{~kg} / \mathrm{m}^{2}$ is approximately the mean plus $\mathrm{SD}$, so that within one SD of the mean BMI is regarded normal or healthy. ${ }^{[16]}$ However, BMI distribution in the general population is skewed towards higher values. ${ }^{[18-20]}$ Therefore, the lower limit of healthy weight is not 15 but $18.5 \mathrm{~kg} / \mathrm{m}^{2}$ in the general population, and the mean is also higher than $20 \mathrm{~kg} / \mathrm{m}^{2}$. Despite this skewness, the widely recognised stages of obesity I $\left(30 \mathrm{~kg} / \mathrm{m}^{2}\right)$, II $\left(35 \mathrm{~kg} / \mathrm{m}^{2}\right)$ and III $\left(40 \mathrm{~kg} / \mathrm{m}^{2}\right)$ are defined in terms of the constant BMI increment of $5 \mathrm{~kg} / \mathrm{m}^{2} .[15,17]$

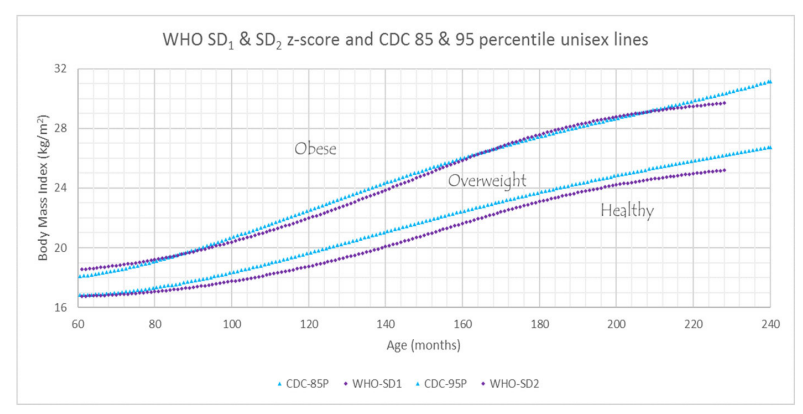

Figure 1. WHO and CDC gender-averaged BMI-for-Age overweight bands

BMI of an average person increases through childhood and adolescence due to the growth, before stabilising upon reaching the adulthood between 18 and 20 years of age. ${ }^{[18-20]}$ The distribution of BMI data in childhood and adolescence is similar to that in adulthood but on a different scale for each year. CDC (Centers for Disease Control in the US), as of year 2000, defined BMI between 85 and 95 percentiles of this distribution for each age as the overweight range, after which persons are regarded obese and before healthy. ${ }^{[20]}$ Despite using this definition is mandatory in the US for official business, ${ }^{[16]}$ a newer definition was proposed by WHO (World Health Organisation) in 2007. ${ }^{[19]}$ In fact, it can be regarded a revised CDC definition as it is based on the same data. A caution was taken to use older data, before the epidemic of obesity. Due to the skewness, percentiles are easier to understand than z-scores (roughly, SD counts) and there are WHO percentile equivalents. At the same time, retrospectively, the WHO definition, based on the notion of SD, allows to connect better to the standard adulthood levels: it is clear that towards 20 years of age the overweight and obese adolescent boundary curves by WHO attain values close to 25 and $30 \mathrm{~kg} / \mathrm{m}^{2}$, respectively, and also level out, which is much different from what is projected using the CDC definition. Otherwise, the overweight bands by WHO and CDC largely 
overlay, as evident from Figure 1, where the gender-averaged bands are compared.

The distribution of data is much more intricate before reaching the age of five years (60 months $)^{[18]}$ and is not considered in the present analysis. Children and adolescents 5 to 19 years of age will be collectively referred-to in this text as juniors. To capture the essence of boundary curve shapes, it is convenient to subdivide the range into five equal parts, each three years long. ${ }^{[21]}$ Indeed, either boundary in the WHO interpretation has three distinct stages. A short pick up stage in the vicinity of five years, a long growth segment, and a shorter stabilisation segment (see Figure 1). At least two more connecting segments are required for a smoother transition between stages, and to accommodate their different durations. Also, there are gender differences. By linearly fitting the pooled male and female data in each segment, using the least squares, ${ }^{[22]}$ trends in the BMI growth can be ascertained. A continuity is achievable by using mean values at junction points, but only a small adjustment was required. Also, to achieve a better, the junction as well as the fit, the segment bounds were stretched by one month, where possible, when acquiring the data. To match the adulthood levels of overweight and obesity with junior corresponding levels at twenty years (240 months), only a slight shift by BMI was then required, which can be assumed being inconsequential for boundary shapes. This made possible representing the boundaries with piece-wise-linear curves, with BMI values at junction points collated in Table 1 .

Table 1. Piece-wise-linear approximation break point BMI $\left(\mathrm{kg} / \mathrm{m}^{2}\right)$ values for selected boundaries

\begin{tabular}{lllll}
\hline Month & Healthy & Right & Overweight & Obese (I) \\
\hline 60 & 12.95 & 14.47 & 15.99 & 18.28 \\
96 & 13.24 & 14.95 & 16.85 & 19.91 \\
132 & 14.32 & 16.34 & 18.80 & 22.94 \\
168 & 16.19 & 18.62 & 21.64 & 26.60 \\
204 & 17.69 & 20.45 & 23.80 & 28.95 \\
240 & 18.50 & 21.50 & 25.00 & 30.00 \\
\hline
\end{tabular}

Included in this table is also the healthy limit and the "right" (mean) level of BMI (tracing the $\mathrm{WHO} \mathrm{SD}_{0}$ curve). The right BMI is assumed to be $21.5 \mathrm{~kg} / \mathrm{m}^{2}$ at 20 years, ${ }^{[23]}$ which guidelines do not specifically quote, but the female data most closely match the adult thresholds overall, and this value is set accordingly. The piece-wise-linear-approximate, anygender overweight and obese boundaries in the Age - BMI space, adjusted to match adult levels at 20 years, are shown in Figure 2 together with the gender-specific boundaries according to WHO. Despite the shift to match the adult levels, and despite being gender-indiscriminate, the approximation can be described as fair throughout, with differences at any point no more than $1.2 \mathrm{~kg} / \mathrm{m}^{2}$.

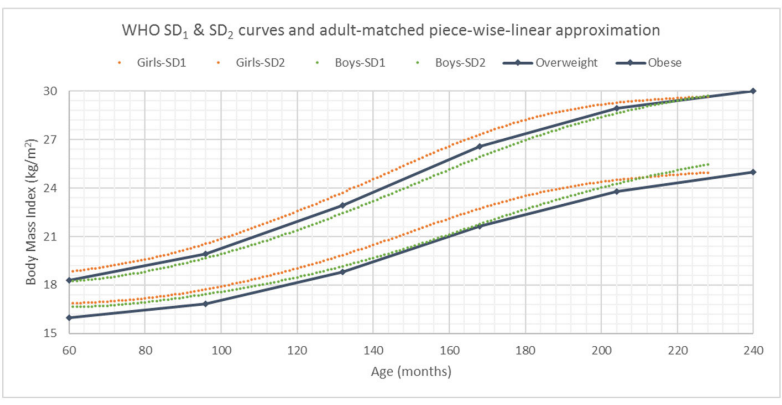

Figure 2. WHO overweight $\left(\mathrm{SD}_{1}\right)$ and obese $\left(\mathrm{SD}_{2}\right)$

BMI-for-Age levels by gender, and the proposed adult-matched, unisex approximation

The waist circumference to height ratio (WCHR), calculated as in Equation 2, is an emergent measure of normalcy/excessiveness of the human body weight, which demonstrates a better utility than BMI in diagnostic of a range of cardiometabolic disorders. ${ }^{[24]}$

$$
\operatorname{WCHR}(\%)=\frac{\mathrm{WC}(\mathrm{cm})}{\text { height }(\mathrm{cm})} \times 100
$$

Here, WCHR is calculated as percentage to force it into a similar value range as BMI and Age, with numbers in this format better perceived; however, this interpretation is not unprecedented. ${ }^{[1]}$ It has been proposed that fixed values of WCHR can serve the purpose of indexing obesity in childhood, adolescence and adulthood alike, by analogy with BMI levels applicable only to adulthood. Particularly, WCHR levels of $40 \%, 50 \%$ and $60 \%$ were proposed for individuals of five years of age or older in the capacity of thresholds akin to the adult BMI levels of $20 \mathrm{~kg} / \mathrm{m}^{2}, 25 \mathrm{~kg} / \mathrm{m}^{2}$ and $30 \mathrm{~kg} / \mathrm{m}^{2}{ }^{2}{ }^{[25]}$ Note that WCHR and BMI are different measures, and each indexing system has its own right. Yet, it is important to know how these different measures conform to each other, and to verify whether the concept of fixed WCHR values for obesity indexing is applicable to the junior contingent of population. This study seeks to address these agendas.

\section{Data}

The required information is routinely captured for the US National Health and Nutrition Examination Survey (NHANES), ${ }^{[26]}$ which is a continuing project coordinated by CDC. Subsets corresponding to five consecutive childhood/adolescence stages, as defined in Table 2, were extracted from a recent NHANES instalment of data (20132014) to test the coherence between obesity indices by age 
frame.

Table 2. Junior respondent age frame descriptors and statistics

\begin{tabular}{lll}
\hline Age $^{*}$ frame & Population (n) & Females (\%) \\
\hline $05+$ & 647 & 47 \\
$08+$ & 593 & 48 \\
$11+$ & 545 & 49 \\
$14+$ & 545 & 51 \\
$17+$ & 453 & 51 \\
\hline
\end{tabular}

Note. *Three-year frames commencing the year noted.

The means and one SD corridors of the apropos anthropometric features through time are plotted in Figure 3 for the data where the attribute values were all known.

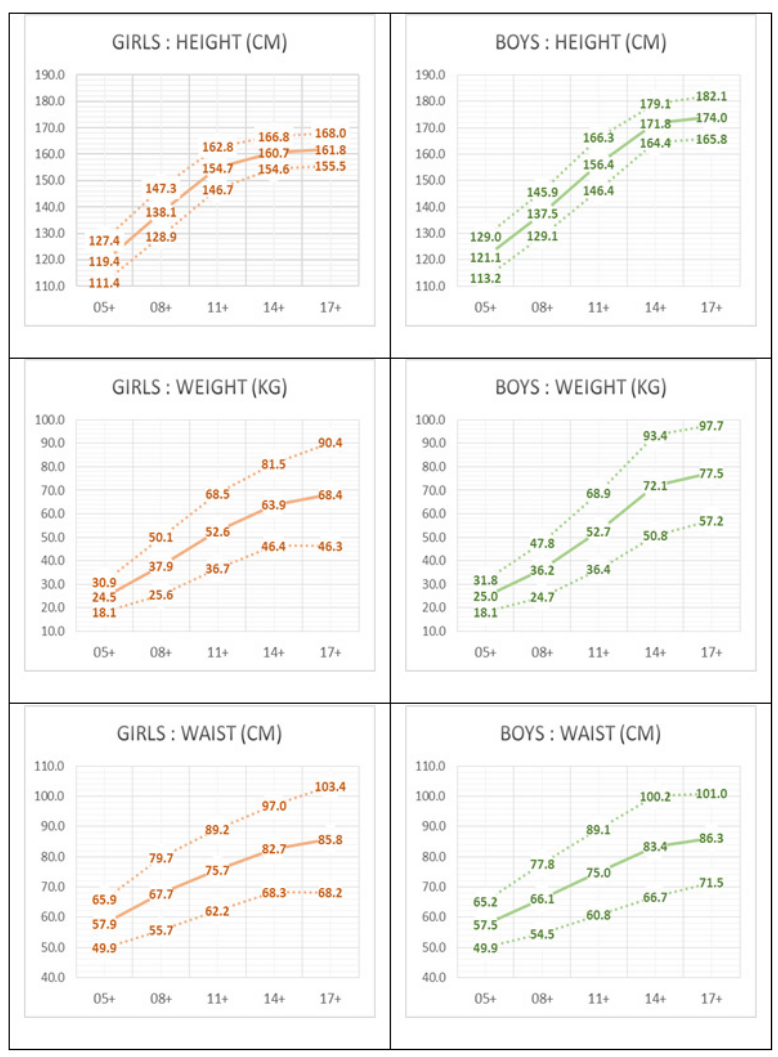

Figure 3. Means and standard deviation ranges of anthropometric features by age frame

The age frame specific means and one SD ranges of obesity measures derived from the anthropometric features depicted in Figure 3 are plotted in Figure 4, illustrating dynamics of the derived measures.

With exception of height, diversity of the data depicted in Figures 3 and 4 is increasing with age. This is noteworthy because in adults the variation is instead decreasing with 4 age, ${ }^{[27]}$ which may be a result of the composite effect of obesity survival. ${ }^{[17]}$ Despite the diversification, the uncompromising nature of height ${ }^{[28]}$ imparts certain stability to both BMI and WCHR. The stability is desirable of a measure. Nonetheless, having compared the results of either measure relative SD averaging over all age categories in both genders, WCHR appears to be $39 \%$ better than BMI in that sense. BMI is expected to increase with age ${ }^{[18]}$ and WCHR presumably not. ${ }^{[25]}$ If the latter holds, this also adds, if not stability, then impartiality to WCHR - a sought after property of a measure. Indeed, as evident from Figure 4, WCHR is increasing at much slower a rate than BMI. However, this seems extraordinary. As seen in Figure 3, weight, waist circumference and height are all increasing with age. Therefore, BMI and WCHR, given by Equations 1 and 2, respectively, should be both held in check; and all other conditions equal, more so BMI than WCHR.

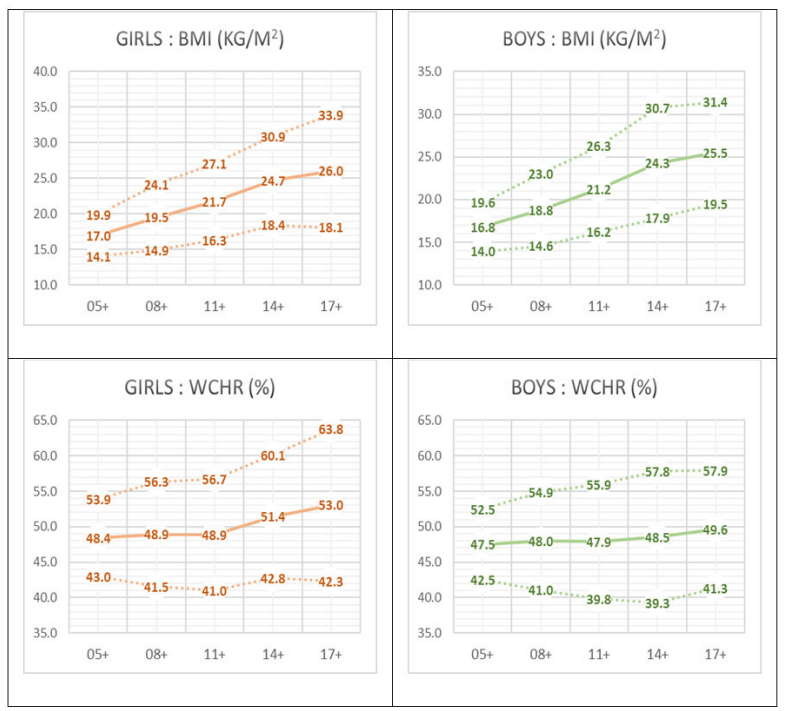

Figure 4. Means and standard deviation ranges of derived anthropometric features by age frame

\section{Methods}

WCHR was linearly regressed on BMI and Age, using the least squares method, ${ }^{[22]}$ by gender as well as indiscriminately. Only data with all three attribute values known was used, but the reduction amounted for less than $5 \%$ of the NHANES original sample. The opposite was also performed, that is, BMI and Age were regressed in turn on two other variables of the three, using the same method and applicable to the subsets arising from data subdivision by gender or the undivided data. Each regression and detrending allowed to identify outliers which were removed once the regression equations (below) for all variables were evaluated. The whole procedure was repeated until outliers were 
no longer detected. The identification of outliers was controlled by specifying the number of SD-s away from the detrended mean of zero, above which the data is considered non-meaningful. The number selected was 3.5 , which is well in excess of 2.0 covering the $95 \%$ confidence interval. Using the same approach and the parameter setting, outliers of WCHR and BMI individual distributions were also identified and removed before regressing either one on the other and Age, cycle after cycle. The above procedure was applied to various subsets of data arising from bootstrapping, which is a sampling with replacement technique. ${ }^{[22]}$ The resampling was required to estimate mean values and confidence intervals for coefficients of regression and also the coefficient of correlation between a particular response variable and the set of explanatory variables (below). For each parameter 250 estimates were obtained. This selection is arbitrary, but with too many repeats the simulation becomes increasingly biased, so the number was set to be less than $10 \%$ of the amount of data. Also, the number of draws of same instance into a sample was limited to 10 , which was to prevent the sample getting too small and imbalanced. At 100 estimates, and draws limited to 5 , the results were much alike.

Equations 3-5, next, represent the reciprocal linear regression expressions for WCHR, BMI and Age.

$$
\begin{aligned}
& \text { WCHR }=\omega_{W}+\omega_{A} \cdot\left(\text { Age }-\alpha_{A}\right)+\omega_{B} \cdot\left(\mathrm{BMI}-\beta_{B}\right) \\
& \mathrm{BMI}=\beta_{B}+\beta_{A} \cdot\left(\mathrm{Age}-\alpha_{A}\right)+\beta_{W} \cdot\left(\mathrm{WCHR}-\omega_{W}\right) \\
& \text { Age }=\alpha_{A}+\alpha_{B} \cdot\left(\mathrm{BMI}-\beta_{B}\right)+\alpha_{W} \cdot\left(\mathrm{WCHR}-\omega_{W}\right)
\end{aligned}
$$

In these equations, $\omega_{W}, \beta_{B}$ and $\alpha_{A}$ are the population WCHR, BMI and Age means, respectively. Otherwise, the subscripts "W", "B" and "A", arbitrarily attached to letters $\omega, \beta$ and $\alpha$, and uniquely identifying a coefficient by the combination, acknowledge the input from WCHR, BMI or Age, respectively. Note that the three equations, although similar, are not equivalent (cannot be transformed into one another). Each equation emphasises the best fit for the response variable of choice, assuming it is dependent on the other two, explanatory variables. Structurally, $\omega_{W}, \beta_{B}$ and $\alpha_{A}$ are the intercepts, and other symbol combinations parameterising Equations 3-5 are the slopes of three planes, represented by the individual equations, in the Age - BMI WCHR space. Together, the parameters define the position and the orientation of each plane, but all three pass through the same point defined by the intercepts (in that sense), which can be thought of as the true origin. The orientation of the three planes is similar, so ideally it is one and the same, with the actual data situated in the vicinity of planes.
Goodness of the linear fit to data is determined by the correlation coefficients $\mathrm{R}_{W}, \mathrm{R}_{B}, \mathrm{R}_{A} \cdot{ }^{[22]}$ For WCHR the coefficient of multiple correlations is defined by Equation 6 .

$$
R_{W}^{2}=1-\frac{\sum\left(W C H R_{i}-\left(W \widehat{C H} R_{i}\right)^{2}\right.}{\sum\left(W C H R_{i}-\omega_{W}\right)^{2}}
$$

In this equation, $W C H R_{i}$ is the actual value, and $W \widehat{C H} R_{i}$ is the estimate using Equation 3; and the summation is done over all instances of data in a sample. The terms in the numerator and the denominator are the residual and the initial, that is, after and before the model is applied, quadratic errors, respectively. The correlation coefficients for BMI and Age are written similarly. A squared correlation coefficient, as in Equation 6, quantifies the proportion of variation of the response variable, it applies-to, explained by variables in its linear expression, in this instance Equation 3.

Fitness of a data model can be also judged by the confidence to magnitude ratio $(\mathrm{C} / \mathrm{M})$ calculated, using Equation 7 , for parameters of the model after the simulated resampling.

$$
C / M=2 \cdot\left(C I_{2}-C I_{1}\right) /\left(\left|C I_{2}\right|+\left|C I_{1}\right|\right)
$$

In this equation, $C I_{1}$ and $C I_{2}$ denote the "from" and "to"

\begin{tabular}{|c|c|c|c|c|}
\hline \multicolumn{5}{|c|}{ Girls } \\
\hline Coefficient & Mean & $\mathrm{CI}_{1}{ }^{*}$ & $\mathrm{CI}_{2}{ }^{*}$ & $\mathrm{C} / \mathrm{M}(\%)^{* *}$ \\
\hline$\omega_{W}$ & 49.29 & 48.78 & 49.80 & 2 \\
\hline$\omega_{A}$ & -0.7067 & -0.7577 & -0.6558 & 14 \\
\hline$\omega_{B}$ & 1.402 & 1.353 & 1.451 & 7 \\
\hline$R_{W}$ & 0.9119 & 0.8998 & 0.9240 & 3 \\
\hline \multicolumn{5}{|c|}{ Boys } \\
\hline Coefficient & Mean & $\mathrm{CI}_{1}{ }^{*}$ & $\mathrm{CI}_{2}{ }^{*}$ & $\mathrm{C} / \mathrm{M}(\%)^{* *}$ \\
\hline$\omega_{W}$ & 47.42 & 46.92 & 47.93 & 2 \\
\hline$\omega_{A}$ & -0.9748 & -1.0253 & -0.9244 & 10 \\
\hline$\omega_{B}$ & 1.474 & 1.421 & 1.527 & 7 \\
\hline$R_{W}$ & 0.9019 & 0.8849 & 0.9189 & 4 \\
\hline \multicolumn{5}{|c|}{ Any gender } \\
\hline Coefficient & Mean & $\mathrm{CI}_{1}{ }^{*}$ & $\mathrm{CI}_{2}{ }^{*}$ & $\mathrm{C} / \mathrm{M}(\%)^{* *}$ \\
\hline$\omega_{W}$ & 48.36 & 47.96 & 48.76 & 2 \\
\hline$\omega_{A}$ & -0.8383 & -0.8754 & -0.8013 & 9 \\
\hline$\omega_{B}$ & 1.436 & 1.399 & 1.472 & 5 \\
\hline$R_{W}$ & 0.9039 & 0.8911 & 0.9167 & 3 \\
\hline
\end{tabular}
bounds of an applicable confidence interval, and $|\cdot|$ stands for absolute values.

Table 3. WCHR (\%) via Age (years) and BMI $\left(\mathrm{kg} / \mathrm{m}^{2}\right)$ regression coefficients

Note. " $\mathrm{CI}_{1}, \mathrm{CI}_{2}$ - confidence interval "from" and "to" bounds; ${ }^{* *} \mathrm{C} / \mathrm{M}(\%)$ - confidence to magnitude ratio as percentage. 


\section{Results}

The regression coefficients and the coefficient of correlation (as in Equation 6) for each of Equations 3-5 are listed in Tables 3-5, for females and males, and also indiscriminate by gender. In these tables $\mathrm{CI}$, given by its bounds $\mathrm{CI}_{1}$ and $\mathrm{CI}_{2}$, is the two SD-s confidence interval, which is an inclusive approximation of the $95 \%$ interval, assuming normality of the coefficient data. The confidence to magnitude ratio $\mathrm{C} / \mathrm{M}$ (Equation 7), also in the tables, is calculated for all coefficients and is expressed as a percentage.

Particularly, substituting the coefficient values from Table 3 into Equation 3, and consulting Tables 4 and 5 for values of BMI and Age intercepts, the gender-indiscriminate WCHR is then expressed via Equation 8 .

$$
\begin{aligned}
\mathrm{WCHR}= & 48.36-0.8383 \cdot(\text { Age }-11.41) \\
& +1.436 \cdot(\mathrm{BMI}-20.60)
\end{aligned}
$$

Similarly, supplying Equation 4 from Table 4, while referring to Tables 3 and 5 for WCHR and Age intercepts, the genderindiscriminate BMI is then expressed by way of Equation 9.

$$
\begin{aligned}
\mathrm{BMI}= & 20.60+0.5995 \cdot(\mathrm{Age}-11.41) \\
& +0.5683 \cdot(\mathrm{WCHR}-48.36)
\end{aligned}
$$

\begin{tabular}{|c|c|c|c|c|}
\hline \multicolumn{5}{|c|}{ Girls } \\
\hline Coefficient & Mean & $\mathrm{CI}_{1}{ }^{*}$ & $\mathrm{CI}_{2}{ }^{*}$ & $\mathrm{C} / \mathrm{M}(\%)^{* *}$ \\
\hline$\beta_{B}$ & 20.94 & 20.57 & 21.30 & 4 \\
\hline$\beta_{A}$ & 0.5289 & 0.5029 & 0.5549 & 10 \\
\hline$\beta_{W}$ & 0.5911 & 0.5713 & 0.6109 & 7 \\
\hline$R_{B}$ & 0.9356 & 0.9272 & 0.9440 & 2 \\
\hline \multicolumn{5}{|c|}{ Boys } \\
\hline Coefficient & Mean & $\mathrm{CI}_{1}{ }^{*}$ & $\mathrm{CI}_{2}{ }^{*}$ & C/M (\%) \\
\hline$\beta_{B}$ & 20.25 & 19.87 & 20.63 & 4 \\
\hline$\beta_{A}$ & 0.6645 & 0.6384 & 0.6906 & 8 \\
\hline$\beta_{W}$ & 0.5519 & 0.5280 & 0.5758 & 9 \\
\hline$R_{B}$ & 0.9386 & 0.9294 & 0.9478 & 2 \\
\hline \multicolumn{5}{|c|}{ Any gender } \\
\hline Coefficient & Mean & $\mathrm{CI}_{1}{ }^{*}$ & $\mathrm{CI}_{2}{ }^{*}$ & $\mathrm{C} / \mathrm{M}(\%)^{* *}$ \\
\hline$\beta_{B}$ & 20.60 & 20.31 & 20.90 & 3 \\
\hline$\beta_{A}$ & 0.5995 & 0.5802 & 0.6189 & 6 \\
\hline$\beta_{W}$ & 0.5683 & 0.5513 & 0.5853 & 6 \\
\hline$R_{B}$ & 0.9346 & 0.9267 & 0.9424 & 2 \\
\hline
\end{tabular}

Table 4. BMI $\left(\mathrm{kg} / \mathrm{m}^{2}\right)$ via Age (years) and WCHR (\%) regression coefficients

Note. ${ }^{*} \mathrm{CI}_{1}, \mathrm{CI}_{2}$ - confidence interval "from" and "to" bounds; ${ }^{* *} \mathrm{C} / \mathrm{M}(\%)$ - confidence to magnitude ratio as percentage.
Likewise, using Table 5 to fill Equation 5, with values of WCHR and BMI intercepts sourced from Tables 3 and 4, the gender-indiscriminate Age is then expressed by means of Equation 10.

$$
\begin{aligned}
\text { Age }= & 11.41+1.106 \cdot(\mathrm{BMI}-20.60) \\
& -0.6119 \cdot(\mathrm{WCHR}-48.36)
\end{aligned}
$$

\begin{tabular}{|c|c|c|c|c|}
\hline \multicolumn{5}{|c|}{ Girls } \\
\hline Coefficient & Mean & $\mathrm{CI}_{1}{ }^{*}$ & $\mathrm{CI}_{2}{ }^{*}$ & $\mathrm{C} / \mathrm{M}(\%)^{* *}$ \\
\hline$\alpha_{A}$ & 11.54 & 11.30 & 11.78 & 4 \\
\hline$\alpha_{B}$ & 1.109 & 1.057 & 1.161 & 9 \\
\hline$\alpha_{W}$ & -0.6245 & -0.6610 & -0.5881 & 12 \\
\hline$R_{A}$ & 0.7701 & 0.7482 & 0.7921 & 6 \\
\hline \multicolumn{5}{|c|}{ Boys } \\
\hline Coefficient & Mean & $\mathrm{CI}_{1}{ }^{*}$ & $\mathrm{CI}_{2}{ }^{*}$ & C/M (\%) ${ }^{* *}$ \\
\hline$\alpha_{A}$ & 11.27 & 11.04 & 11.51 & 4 \\
\hline$\alpha_{B}$ & 1.121 & 1.078 & 1.163 & 8 \\
\hline$\alpha_{W}$ & -0.6156 & -0.6428 & -0.5885 & 9 \\
\hline$R_{A}$ & 0.8631 & 0.8500 & 0.8761 & 3 \\
\hline \multicolumn{5}{|c|}{ Any gender } \\
\hline Coefficient & Mean & $\mathrm{CI}_{1}{ }^{*}$ & $\mathrm{CI}_{2}{ }^{*}$ & C/M (\%) ${ }^{* * *}$ \\
\hline$\alpha_{A}$ & 11.41 & 11.24 & 11.58 & 3 \\
\hline$\alpha_{B}$ & 1.106 & 1.074 & 1.138 & 6 \\
\hline$\alpha_{W}$ & -0.6119 & -0.6329 & -0.5910 & 7 \\
\hline$R_{A}$ & 0.8154 & 0.8031 & 0.8277 & 3 \\
\hline
\end{tabular}

Table 5. Age (years) via BMI $\left(\mathrm{kg} / \mathrm{m}^{2}\right)$ and WCHR (\%) regression coefficients

Note. " $\mathrm{CI}_{1}, \mathrm{CI}_{2}$ - confidence interval "from" and "to" bounds; " $\mathrm{C} / \mathrm{M}(\%)$ - confidence to magnitude ratio as percentage.

As seen from Tables 3-5, the correlation coefficients $\mathrm{R}$ for the data not subdivided by gender are very stable, with $\mathrm{C} / \mathrm{M}$ only $2 \%-3 \%$, and jointly signal a high linearity between WCHR, BMI and Age. Particularly, $\mathrm{R}_{\mathrm{W}}$ and $\mathrm{R}_{\mathrm{B}}$ are about 0.9 , that is, within the immediate reach of unity, and so perfect linearity, with BMI performing somewhat better than WCHR. It is surprising, though, that $\mathrm{R}_{\mathrm{A}}$ is also no less than 0.8 , implying that it is feasible to determine junior age by BMI and WCHR, appearing to complement each other. The slopes of linear regressions in Equations 3-5 are expected to be more sensitive than the intercepts, which evidently holds. After all, the intercepts are estimated using the genuine, same-point data, and the slopes have to draw on the neighbouring points in the multidimensional space.

After performing the paired two-tailed $t$-Test (Excel) on the generated parameter data, all regression coefficients in Tables 3-5 are statistically distinct for males and females $(p<.001)$. 
Even though the regression coefficients depend on gender, they are close, justifying linear expressions evaluated from all data.

Take any of Equations 8-10, WCHR is increasing with BMI but decreasing with Age. Indeed, if the data is examined by age frame, as provided-for in Figure 5, there is an increase of WCHR with BMI in any of the age frames, which can be expected. However, somewhat paradoxically, there is indeed a reduction of WCHR with Age at fixed BMI. This was also observed elsewhere. ${ }^{[1]}$ In adults, WCHR tends instead to increase with age, given BMI. ${ }^{[27]}$

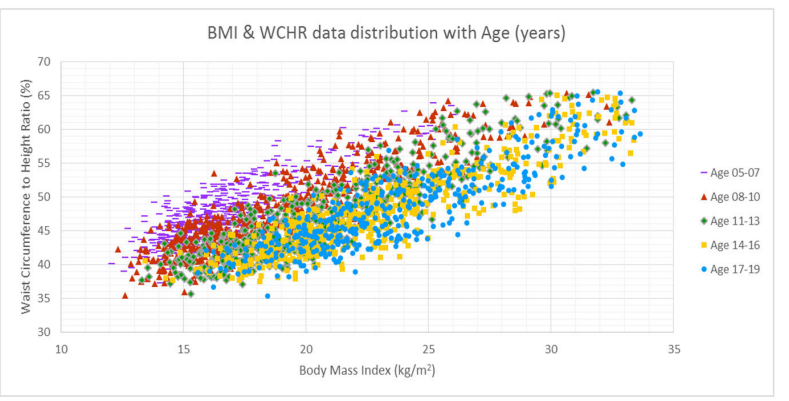

Figure 5. BMI \& WCHR data point mapping for consecutive three-year Age frames

The data image in the BMI - WCHR plane, plotted in Figure 5 , does not include points identified as outliers (less than $5 \%$ of the data). It is based on all participants, undivided by gender. Similar results are obtained for individual genders.

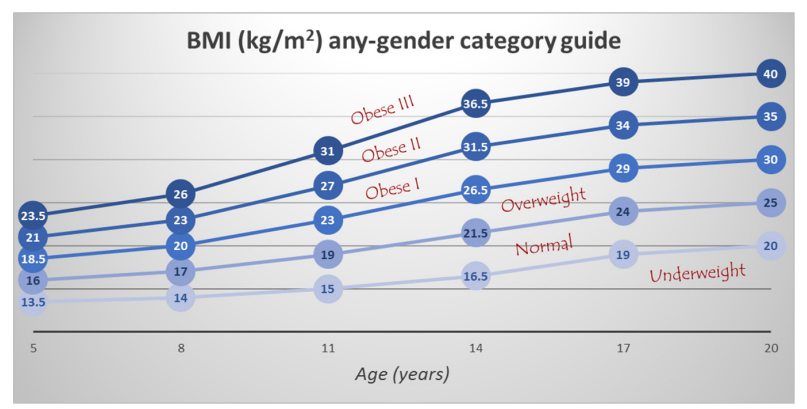

Figure 6. Unisex BMI category guide based on WHO definition of overweight

\section{Discussion}

\subsection{BMI categories}

In the introduction, the overweight state and the obesity boundaries in the Age - BMI space for juniors were aligned with corresponding BMI thresholds for adults. CDC and WHO are not specific as to how other categories for the junior contingent should be defined. For adults, the standard $5 \mathrm{~kg} / \mathrm{m}^{2}$ shift for categories higher than overweight

Published by Sciedu Press applies. This shift fairly closely approximates the BMI distance between $\mathrm{SD}_{1}$ and $\mathrm{SD}_{2}$ lines arising from the underlying z-scores of 1 and 2 of the distribution, respectively, upon reaching the adulthood. The distance between consecutive SD lines should increase as the scores become larger, but the same distance applies by definition in adulthood. This is convenient because, realistically, there are only few more categories above the overweight as the population yet unaccounted-for falls sharply (preview Figure 7). Any increase in the category span, if the z-score specification were followed, is thus neglected, but it is only important how the escalation is detrimental for health, and the $\mathrm{z}$-score does not necessarily reflect this. The bottom line is that the standard, seasoned definition of the overweight and the three obesity stages is a constraint imposed on the data concept. The standard rules set a bare minimum for the healthy adult weight at BMI of $18.5 \mathrm{~kg} / \mathrm{m}^{2}$. In the US the limit is set officially by the CDC 5-th percentile approximating the standard level for adults. ${ }^{[16]}$ This corresponds to the WHO $\mathrm{SD}_{-1}$ line in the junior range, but it defines "thinness" by the $\mathrm{SD}_{-2}$ level, perhaps to mirror the obesity. However, due to the data compression towards smaller BMI values, even the $18.5 \mathrm{~kg} / \mathrm{m}^{2}$ is very low. Prevalence of population who are lighter is negligibly small, for which an abundant evidence exists, and particularly this holds for NHANES. ${ }^{[29]}$ Some texts subtract $5 \mathrm{~kg} / \mathrm{m}^{2}$ from the overweight BMI threshold at $25 \mathrm{~kg} / \mathrm{m}^{2}$ to define the normal and the underweight categories. ${ }^{[25]}$ These categories are though expressly different from the healthy and unhealthy ones, above and below $18.5 \mathrm{~kg} / \mathrm{m}^{2}$ by BMI, respectively. Setting the minimum for normal BMI at $20 \mathrm{~kg} / \mathrm{m}^{2}$ has a number of merits. Firstly, all BMI categories become equally spaced. Secondly, the underweight category becomes a nontrivial one, with some population to size up. Above all, this threshold is still lower than the "right" BMI, discussed in the introduction, which is $21.5 \mathrm{~kg} / \mathrm{m}^{2}$ for adults. ${ }^{[23]}$ In fact, it is half-way between the healthy and the right. It makes sense to embrace this uniform approach for the junior population, and it is achievable by distancing BMI category levels at any age by the width of the overweight band. With the piece-wise-linear approximation in hand, it is then only required to set the thresholds at specified ages. Using data from Table 1, firstly the category span, applicable to all BMI categories, is determined by subtracting the overweight level from the obese one. Thus obtained the universal category span for a specified age is rounded to the closest 0.5 to manage the error and for ease of applying. The span is then added or subtracted a required number of times from the overweight threshold for that age, rounded likewise. The rational for such a presentation is that BMI is realistically known to one decimal place. The limited precision is prob- 
lematic independently for the small age where the spectrum becomes too narrow. The resulting gender-indiscriminate BMI category guide is posted in Figure 6.

Applying this guide to the NHANES data, the population division by BMI category regardless of gender renders the pie chart shown in Figure 7.

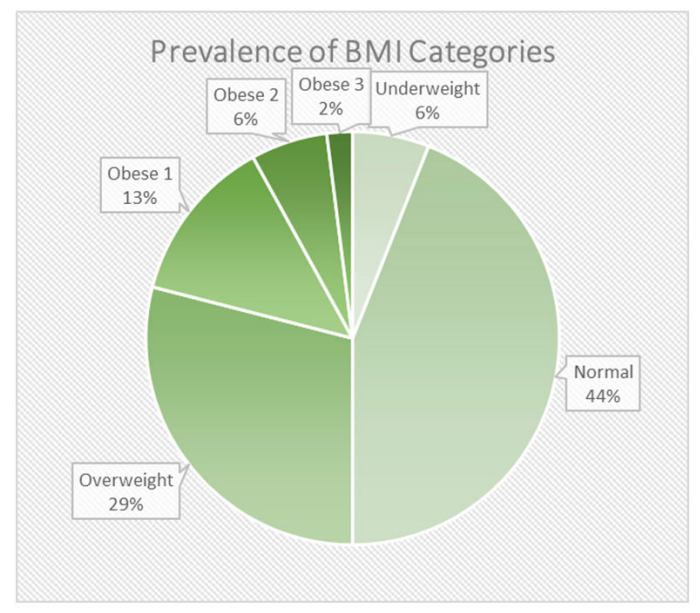

Figure 7. BMI category population break-up for NHANES

Small categories present a problem for data evaluation as the input from chance becomes measurable. Particularly, the third obesity categorisation applies only to 40 female and 15 male participants. While the category is small, the indication for bariatric surgery for juniors is set by the third obesity threshold for adults (at $40 \mathrm{~kg} / \mathrm{m}^{2}$ ), ${ }^{[15]}$ so without a guide, like the one in Figure 6, at least some of the eligible population could be missed out. The guidelines are short of advice applicable to juniors, whilst clear indications for lifestyle modification and pharmaceutical treatment exist for adults.

Table 6. Piece-wise-linear approximation break point WCHR (\%) values for selected boundaries

\begin{tabular}{lllll}
\hline Month & Healthy & Right & Overweight & Obese (I) \\
\hline 60 & 42.75 & 44.93 & 47.11 & 50.40 \\
96 & 40.65 & 43.11 & 45.83 & 50.23 \\
132 & 39.69 & 42.59 & 46.12 & 52.06 \\
168 & 39.86 & 43.35 & 47.68 & 54.80 \\
204 & 39.50 & 43.46 & 48.27 & 55.66 \\
240 & 38.14 & 42.45 & 47.48 & 54.66 \\
\hline
\end{tabular}

\subsection{WCHR categories}

Using overweight and obese BMI from Table 1 makes possible obtaining an image in the Age - WCHR plane by applying the transformation given by Equation 8. In virtue of linearity of the transformation, either boundary image is piece-wise- linear as well. All other boundaries in the Age - WCHR space can be obtained in the same manner. Table 6 is the transformed Table 1 using Equation 8.

Using the data in Table 6 and adopting the same approach that led to BMI categories in Figure 6, allows for compilation of the WCHR category guide presented in Figure 8. Note that about the same is achievable by applying the linear transformation directly to the data from Figure 6, but is not pursued because of the rounding that had been applied.

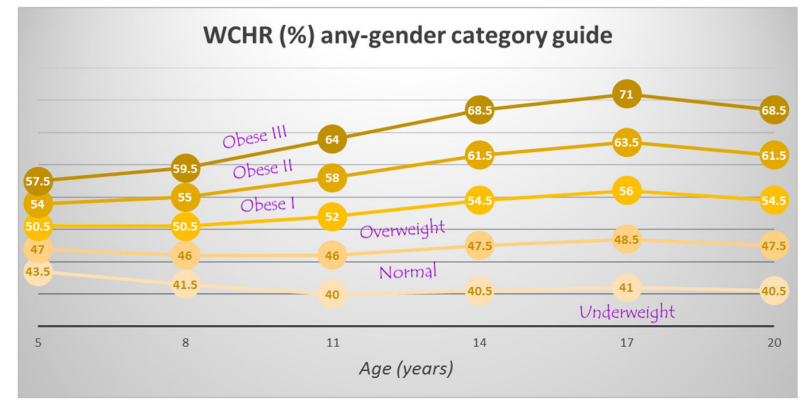

Figure 8. WCHR category guide based on WHO BMI-for-age overweight ranges

One distinction of this guide comparing to the original is that, despite WCHR measurements would usually provide the same one decimal place, the resolution offered by the measure is somewhat higher than in BMI, which makes it more appropriate for small-age categories. However, the main distinction of the WCHR category guide comparing to the BMI original is that WCHR on a boundary does not necessarily increase with Age. A special feature of the WCHR image is that the amplitude of change is increasing with category. Particularly, the overweight level is $47.1 \% \pm 0.9 \%$, whereas the obesity level is $53.0 \% \pm 2.2 \%$, using data from Table 6 to calculate the means and SD-s. Also, while higher categories can be described as having an increasing boundary trend and lower as somewhat decreasing, as evident from Figure 8, the trend of the overweight state boundary is the least determined throughout the junior range. The overweight level is about $47 \%$ regardless of age. The same is true in respect of any other boundary in the adolescent range. Roughly, the WCHR levels at 14 years apply onwards.

Following the guidance provided by Figure 8, the prevalence of WCHR categories in the NHANES population regardless of gender is as laid out in Figure 9. Comparing to Figure 7, there is a redistribution amounting to $5 \%$ of data in the chart shown in Figure 9: there is $3 \%$ gain in the underweight and $1 \%$ gain in each of the obesity stage 2 and 3 categories, all at expense of the normal weight (4\%) and the overweight (1\%) categories. This is consistent with WCHR being more sensitive, and BMI more specific than the other measure in 
determining T2DM status in adults. ${ }^{[27]}$ The classifications by either measure are expected to be close, and the little disagreement only affirms this conjecture. However, comparing frequencies is only able to provide a grand view.

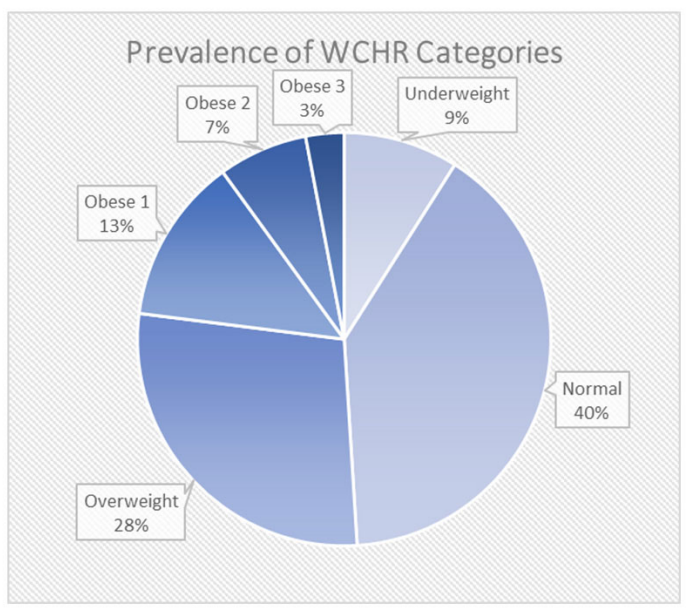

Figure 9. WCHR category population break-up for NHANES

\subsection{Correspondence between BMI and WCHR cate- gories}

It is impossible that for all instances of data WCHR fell into a category equivalent to the one defined by BMI, just because the two metrics are different and there are borderline instances which existence is purely circumstantial. Also, having a category wide enough, a very close match can be achieved, but the opposite is also true. Particularly, unlike in adolescence, the BMI category levels applicable to childhood are very close to each other (see Figure 6), increasing the probability of misclassification. However, the two metrics are perceived as equivalent in assessing the excessiveness of body weight, and the account is incomplete without testing the allegiance of alternative measures to one another.

Firstly, a common denomination is required. One could think of a measure-independent obesity index where category boundaries are given by whole numbers. Suppose 0 or more defines the normal weight, 1 or more the overweight state, 2 or more the first stage of obesity, and so on. Apart from known ones, more categories below or above can be added, although these are unlikely to be meaningful due to lack or unavailability of the data which, physiologically, has its limits. Due to the design, all that is required to convert BMI and WCHR to this unifying Obesity Index (OI) is a pair of linear transformations given by Equations 11 and 12, next, where the subscripts "N", "W" and "O" mark lower bounds for the normal weight, the overweight state and the first obesity stage, respectively. The required bounds can be evaluated for any age using data found in Figures 6 and 8 and applying the piece-wise-linear approximation.

$$
\begin{aligned}
& \mathrm{OI}(\mathrm{BMI})=\frac{\mathrm{BMI}-\mathrm{BMI}_{\mathrm{N}}}{\mathrm{BMI}_{\mathrm{O}}-\mathrm{BMI}_{\mathrm{W}}} \\
& \mathrm{OI}(\mathrm{WCHR})=\frac{\mathrm{WCHR}-\mathrm{WCHR}_{\mathrm{N}}}{\mathrm{WCHR}_{\mathrm{O}}-\mathrm{WCHR}_{\mathrm{W}}}
\end{aligned}
$$

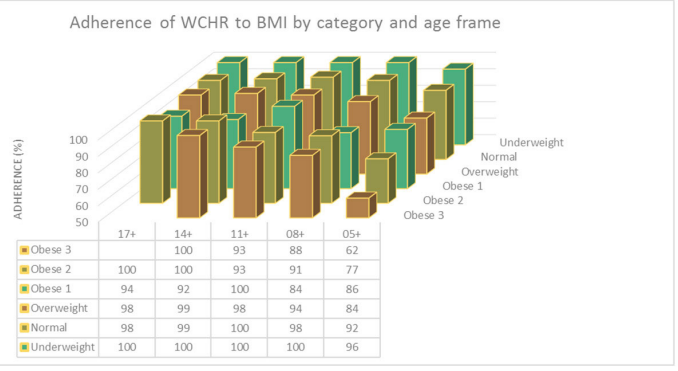

Figure 10. WCHR and BMI obesity index one category width proximity rate by category and age frame

The number of matching classifications cannot be an accurate gage of similarity of the two measures, as noted. Perhaps, it is possible to harness the continuous spectrum to arrange for a comparison. One approach is to calculate the absolute differences between $\mathrm{OI}(\mathrm{WCHR})$ and $\mathrm{OI}(\mathrm{BMI})$, and measure them up to the category span which for OI is 1 in virtue of the transformations defined by Equations 11 and 12. A comparison task could be formulated, for example, as follows: verify whether $\mathrm{OI}(\mathrm{WCHR})$ and $\mathrm{OI}(\mathrm{BMI})$ are less distant than 1. The results of such a comparison are shown in Figure 10 by BMI category and age frame. All unnamed categories defined by whole numbers below -1 or above 4 , if any, are included with the underweight or the third obese category, respectively. The data frequency is an important aspect of the comparison, as the falling frequency is raising stakes for the chance, making the result less reliable in categories at fringes of the spectrum. Specifically, the second and the third obesity categories are small whether by BMI (see Figure 7) or WCHR (see Figure 9) and the results may be unreliable. Here, the data is analysed by age frame and this circumstance is especially of concern. Particularly, the 17+ age frame has no data at all in the third obesity category. However, this consideration is less relevant for the outer categories, unbounded at one end. For higher age frames the adherence between BMI and WCHR within the specified range (one category span) is close to perfect throughout. This degree of perfection is remarkable, as it measures up to the choice of $5 \mathrm{~kg} / \mathrm{m}^{2}$ as the BMI unit by convention. The rate decline in the direction of younger age is probably due to the described narrowing of BMI and WCHR categories in that direction, as seen in Figures 6 and 8, besides increasing the conversion 
error. Otherwise, at least for the $5+$ and the $8+$ age frames, there is a clear decline in the rate of adherence between the two measures as the OI category advances.

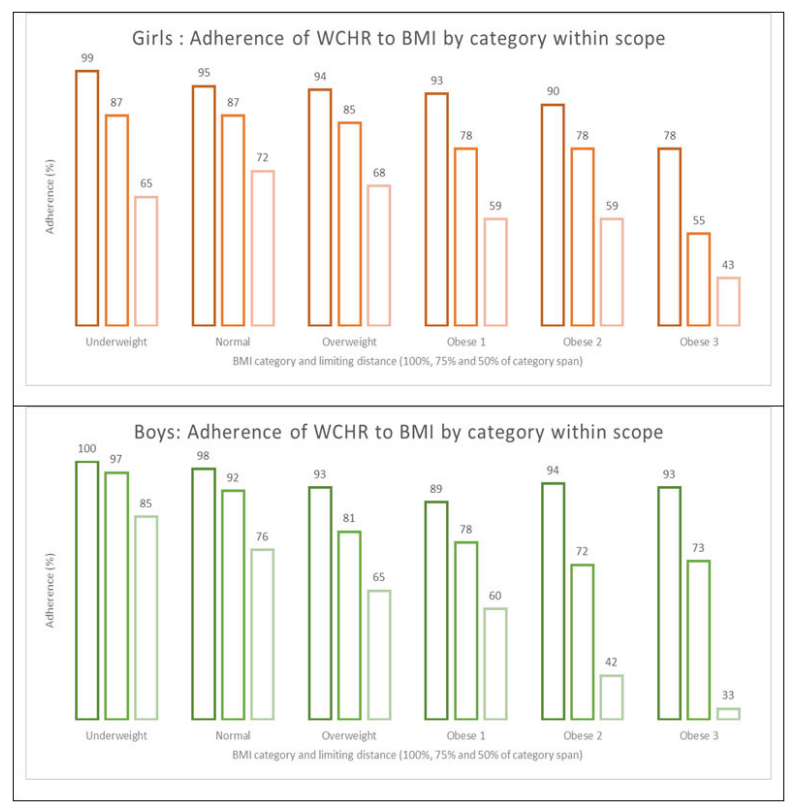

Figure 11. WCHR and BMI obesity index varying admissible proximity rate by category

The value of the conducted test is that it has demonstrated a uniform, top-notch result in different age frames, except for the first two where the loss of accuracy is unavoidable. On the other hand, too much detail was involved, risking an unsound statistical inference. The downside of such a test is though that, if it is successful, one category width can only guarantee that WCHR and BMI point to adjacent categories, the same category at best. Therefore, a better understanding of degree of adherence of the two measures requires that the allowed gap varied. In Figure 11, the results for distances of $100 \%$ (same as in the previous test), $75 \%$ and $50 \%$ of the category span (OI distance of 1.00, 0.75 and 0.50) are compared by BMI category and by gender.

There is a great deal of resilience when the scope is narrowed, yet clearly the first $25 \%$ reduction is yielding less than the second, indicating a wide dispersion. The situation is similar in both gender contingents, although in males the third and the second obesity stage results for the $100 \%$ interval are probably unreliable, as previously noted. There is a clear, and tentatively increasing slide of the adherence rate in the direction of higher BMI categories for all attempted admissible proximities, which exposes a hidden nonlinearity in the relationship between WCHR and BMI. WCHR and BMI become more incoherent as the obesity progresses.

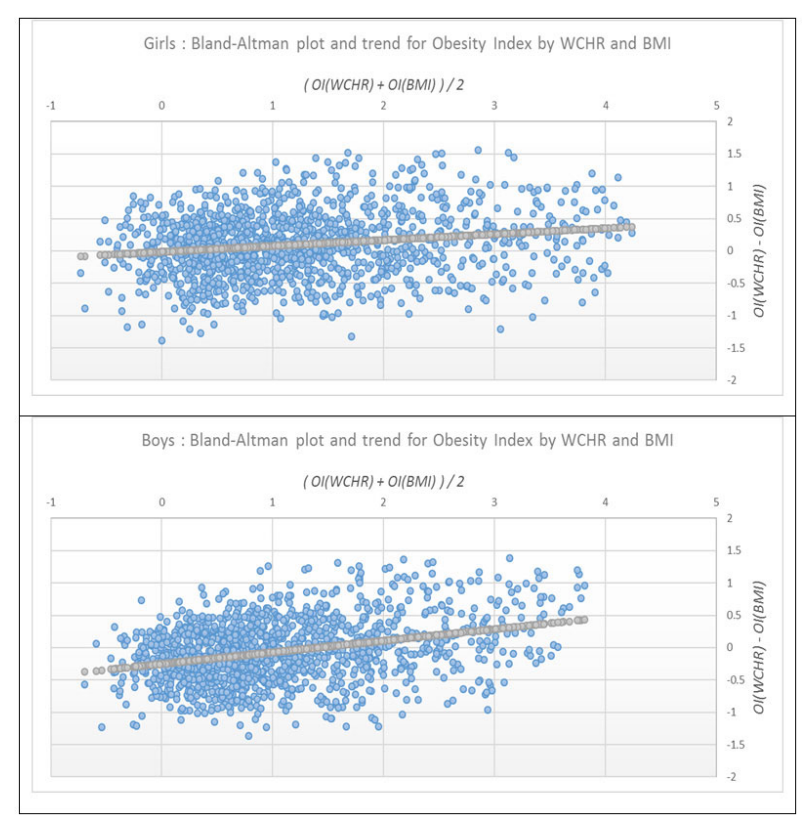

Figure 12. WCHR vs. BMI obesity index Bland-Altman plots

The difference between $\mathrm{OI}(\mathrm{WCHR})$ and $\mathrm{OI}(\mathrm{BMI})$ is largely explained by unique properties of BMI and WCHR, despite the great deal of linearity between measures. A tool provided by Bland-Altman plot gives some insight into the degree of randomness of the difference between two measures presumably of the same. It plots mean of the two values against directional difference between the two. The plot, applicable to the situation in hand, is shown in Figure 12. If the two measurements of the same are different only by chance then there should be no increase or decrease in the magnitude of difference between the two, as defined by the trend. Here, despite the lack of correlation between the mean and the difference, there is clear tendency to the difference increase with the mean. In other words, WCHR tends to assign a higher obesity category comparing to BMI, and this tendency becomes bolder towards the high end of either measure distribution. This is true for both males and females but more strongly expressed in males. The difference increase is by $9 \%$ for females and $18 \%$ for males per category span. The lesser tendency to category escalation in females, when using WCHR as opposed to BMI, can be explained by largely gluteal-femoral deposition of fat after puberty (gynoid body type). In males the deposition tends to be about the abdomen (android body type) regardless of age, thus increasing WCHR. ${ }^{[30]}$

Nonetheless, not always $\mathrm{OI}(\mathrm{WCHR})$ is larger than $\mathrm{OI}(\mathrm{BMI})$. The trend line in Figure 12 crosses the zero difference line in females at 0.17 , that is, close to the normal weight segment beginning, and in males at 1.41 , that is, about the overweight 
segment middle. Below these mean values of OI, BMI actually has the upper hand over WCHR, which explains the larger prevalence of underweight population by WCHR, in Figure 9, than by BMI, in Figure 7. Due to this change of direction and the fact that more than $80 \%$ of population is concentrated in the normal, the overweight and the first obese categories, whichever is the measure, with numbers almost halving from one category to next, the impact of listing of Bland-Altman plots is, however, limited. Also, the residual of the trend gives an idea how statistically different the measures otherwise are, with SD of $49 \%$ and $46 \%$ of the category span in females and males, respectively. This indiscriminate admixture to the variation should be more of concern due to its magnitude and omnipresence than the plot listing, but perhaps its impact can be less if the techniques of measure taking for body weight and waist circumference were improved. Again, these results can only guarantee that the two classifiers will not assign any appreciable amount of data to categories not immediately following each other. Interestingly, a polarisation of results is observed if the mean of $\mathrm{OI}(\mathrm{WCHR})$ and $\mathrm{OI}(\mathrm{BMI})$ is replaced by one of the components in a would-be Bland-Altman plot. When OI(WCHR) and $\mathrm{OI}(\mathrm{BMI})$ difference is plotted against $\mathrm{OI}(\mathrm{WCHR})$, the listing is stronger than for their mean, but it is all but present when plotted against $\mathrm{OI}(\mathrm{BMI})$, with a slightly negative trend for females and a slightly positive trend for males. The latter is important as this validates the method. After all, WCHR was regressed on BMI, not in reverse. Otherwise, the variation against the trend is similar in any of the plots. With this in mind, it can be estimated that roughly $60 \%$ of WCHR and BMI measurements are fully concomitant in either gender, with the rest of WCHR in terms of BMI split between the previous and the next category, but redistributing according to the trend as the focus changes. While some of the WCHR equivalents fall outside the BMI category in the focus, most are found close to its boundaries.

\section{RELATED WORK}

\subsection{Overweight and obese WCHR}

Other published best cut-off points by WCHR for identifying, broadly, an overweight state, an obese state, or a metabolic syndrome in junior populations are as shown in Table 7. If a metabolic syndrome specification was the criterion, the threshold is also interpreted as a transition point to either an overweight/low-risk or an obese/high-risk state, to facilitate the discussion. Where the results were not available for entire populations but separately for males and females, their joint means are shown. The age range for the American (USA) study is approximated.

Table 7. Published WCHR cut-off points for various criteria

\begin{tabular}{llllll}
\hline \multirow{2}{*}{ Population/Study } & \multirow{2}{*}{ Subjects (n) } & \multirow{2}{*}{ Age range (years) } & \multicolumn{2}{c}{ WCHR threshold (\%) } \\
\cline { 5 - 6 } & & & Overweight state & Obesity & Metabolic syndrome \\
\hline Mexican ${ }^{[31]}$ & 110 & $8-16$ & 49 & 60 & 60 \\
Brazilian $^{[32]}$ & 175 & $6-10$ & 50 & 50 \\
USA (Hispanics) $^{[8]}$ & 219 & $9-12$ & 54 & 54 \\
Portuguese $^{[33]}$ & 517 & $15-18$ & 46.5 & 46.5 \\
South-African $^{[34]}$ & 1,272 & $10-16$ & 45.5 & 47.5 & \\
Australian $^{[21]}$ & 2,773 & $8-16$ & 44.5 & 48.0 & \\
Chinese (Uygur/Han) $^{[35]}$ & 4,187 & $8-18$ & & \\
\hline
\end{tabular}

Usually, the cut points are calculated by maximising the sum of sensitivity and specificity (the Youden's index plus one) - the two components of predictive accuracy for a specified condition or its absence in the receiver operating characteristic (ROC) analysis framework. In this instance, sensitivity quantifies the success rate for presence of the overweight state/obesity/metabolic syndrome, and specificity for absence of the condition. The American, South-African and Chinese studies are true to this objective. Instead of maximising the sum of sensitivity and specificity, the Mexican study minimises the sum of their squared complements to unity, which is similar. The Portuguese and the Australian studies do not discuss the method but the standard one should be as- sumed. Only the Brazilian study is somewhat different, with emphasis on sensitivity rather than specificity.

However, the criteria measured-against are widely different. With regard to the overweight/obesity threshold evaluations, the American study uses the Fitnessgram project standards which are based on percent body fat converted to BMI percentiles that are intended to meet certain elevated or imminent metabolic risk criteria. ${ }^{[36]}$ These percentiles are different for males and females and generally are lower than the CDC percentiles but within 5 points of respective boundaries. ${ }^{[8]}$ The overweight state corresponds to the nascent metabolic syndrome in this classification. ${ }^{[8]}$ This is argued 
to have more sense than the conventional CDC or WHO standards that are simply based on characteristics of data distribution and are not specifically associated with health risks. The Australian study targets overweight and obese states based on British percentiles for percent body fat. The Chinese study is consistent with how the overweight and obese states are conventionally defined, but uses BMI-forage charts purposely developed for the population type in study, for which a much larger array of data than the sample was used.

The metabolic syndrome (MS) is commonly defined as a clustering of at least three of the following risk factors: high blood pressure, elevated triglycerides, reduced high density lipoprotein cholesterol, poor glycaemic control, and large waist circumference. ${ }^{[3]}$ One interpretation makes large waist circumference a mandatory risk factor for MS. ${ }^{[3]}$ Fixed levels of these components identify elevated health risk levels in adults, but there is an ambiguity about how the definition of MS is applied to juniors. In practice, fixed levels, even though more appropriate for junior populations are used just the same ${ }^{[32,34]}$ where growths charts are unavailable. ${ }^{[19,20]}$ The Mexican study is unique by applying percentiles for all MS components but the fasting glucose, previously developed for that type of population. The MS is not a disease but may develop into HT and T2DM, and eventually CVD. It is, however, essential to be able to detect MS in juniors because T2DM and more so CVD may be subclinical for a long time, which may take well into adulthood before the disorders become frank or are diagnosed. ${ }^{[2,3]}$ Because MS is not a disease, its definition is often not strictly followed. Only the South-African study uses the conventional definition of MS. The Mexican and the American studies adopt definitions of MS which can be considered equivalent to the conventional one. The Brazilian study finds different cut-off points for various markers of metabolic risk, but close to each other, which average is shown in the table. The markers include some of the standard set for MS. The Portuguese study calculates a self-defined metabolic risk score for which unacceptable elevation the cut-off point is found as shown. The applied method removes the necessity to use fixed thresholds for included components, but the present and absent risk categories depend on the sample, and so are not universal. Otherwise, the risk components in the study are not all the standard ones for MS.

All studies in Table 7, except for the Australian, do not pursue the dependence of WCHR thresholds on age. The Australian study uses 8-10, 11-13 and 14-16 years age frames, followed presently; however, it finds no differences in WCHR levels pertaining to these age ranges. This falls favourably with the result in the current work (see Figure 8) with respect to the overweight threshold, despite the interpretation of how it is set, but not the obesity threshold. Also, the obesity and the overweight thresholds, estimated in the Australian study, seem to be positioned too close to one another. One possibility is that the largely pre-epidemic data was used, and the numbers in the overweight and especially the obese categories may be small (unreported), making the choice difficult. The overweight category width is larger in the Chinese study, and the fact that the overweight threshold is lower than the estimated presently (see Figure 8 ) is explainable by racial differences. ${ }^{[24]}$ Yet, the narrower overweight range, than might be anticipated, may be due to the presumed fixed value for the obesity threshold, whereas the current result suggests it may vary with age. One problem shared by the Australian, Chinese and as well as the American study is though that the "overweight" segment includes also all obese, and the "obese" segment all stages thereof. This could have pulled the overweight threshold up and the obesity threshold down, but how depends on the data.

The up-to-date obesity guidelines recommend using WCHR in excess of $50 \%$ or inclusive as a pre-assessment criterion justifying further consideration of cardiometabolic risks in a child. ${ }^{[15]}$ This acknowledges the lack of convenient tools for obesity assessment applicable to juniors. However, this criterion is much better researched for adults, and is based on a broad consensus involving various criteria as to how the cardiometabolic risk is determined: a MS; a diagnosed HT, $\mathrm{T} 2 \mathrm{DM}$ or CVD; ${ }^{[24]}$ spare the ethnical and racial variation. It can be argued that the overweight threshold in Table 7 expresses a degree of cardiometabolic risk similar to that matching MS criteria, ${ }^{[8]}$ whereas obesity should be more aligned with HT, T2DM and CVD that are advanced stages comparing to MS at onset. However, having HT, T2DM or CVD in addition to MS does not change its status. In fact, some sources regard T2DM complicated by HT the MS. The participants in the Mexican study are all obese, using the BMI percentiles, by design. This explains that the cutoff point for MS is much higher than the assumed $50 \%$ by WCHR. Therefore, this point is more suited for describing advanced stages of MS. The 50\% reported in the American study is also probably at the high end of the distribution as the authors emphasise the population ethnicity and "economic" background, predisposing-to and abetting obesity. The weighted average of all thresholds descriptive of an overweight state/elevated cardiometabolic risk in Table 7 is $47 \%$ for non-Asian populations, and some authors imply that this value should be less than $50 \%$ for juniors. ${ }^{[21,32,34]}$ The aforementioned Australian guidelines refer to a pilot study that only verified the WCHR 50\% threshold for adolescents. ${ }^{[37]}$ Further, it can be expected that the overweight threshold is 
increasing with age past the adolescence. ${ }^{[27]}$

\subsection{Population height increase}

Take BMI or WCHR - the taller, the healthier. In economics, the body height has been long known as a reliable estimator of the per-capita gross national product and, more generally, the standard of living. The body height was used for personal identification before the photography, and national archives are likely to store this kind of information. Much less historical data is available on the gross domestic product, and a conversion to current values presents certain challenges. Times of famine are correlated with the affected population height reduction, and times of rising economy with height increase. ${ }^{[28]}$ Recent reviews document an accelerated increase of population height in developed countries, less so in developing countries. ${ }^{[38]}$ The increase is attributed to favourable environmental conditions, including the level of income, evenness of its distribution, the quality and accessibility of health care, much less to the genetic factors. In Europe, nations who were not involved in devastating wars of the past century, or escaped the "totality" of war, are remarkably taller than nations, even closely related ones, who were directly involved; but historically the differences did not register. ${ }^{[28]}$ Scandinavian countries and the Netherlands are now ahead of other countries in Europe, particularly Germany and Belgium. ${ }^{[38]}$ South Koreans appear being taller than North Koreans, underscoring the difference in economic systems, although only limited data is available. ${ }^{[39]}$ Surely, the population height increase offsets the indicators of obesity epidemic in developed countries. ${ }^{[10]}$ The current views are that much of the height is gained in the first two years of life with a proper nutrition. ${ }^{[38]}$ A lesser role is given to the secondary growth before puberty. However, too fast a growth in the first two years may result in the early "adiposity rebound", that is, reaching the BMI minimum before the age of 5 years. ${ }^{[14]}$ This would predispose to fatness later in life, and does not add up with the notion of height being a remedy for obesity. Intergenerational factors, that is, transfer of some features, particularly height, from a mother to her child due to birth-giving, are also being debated. ${ }^{[38]}$ An over-nutrition in childhood should be seen in this light. ${ }^{[3]}$ Therefore, the guidelines do not recommend any particular intervention, apart from the advice of moderation, as children have the ability to "grow into their weight". ${ }^{[15]}$ However, timing is essential as the pre-existing obesity may precipitate puberty. ${ }^{[2]}$ The advice applies less to adolescence where the intensity of growth is reduced. For example, the blood pressure, although in both contingents, is increasing with age/height; and the total cholesterol, at least between years 10 and 16, is at-all in a steep decline. ${ }^{[3]}$ In summary, the obesity as a phenomenon impacting health and correlating with over-nutrition appears

Published by Sciedu Press to be self-correcting in respect of the evolving population. Taking into account the proven beneficial effects of height for wellbeing and the tendency to height increase across the globe, the fears of a new wave of obesity epidemic due the generational change can be therefore overrated. Albeit, being taller does not necessarily mean healthier, in general, ${ }^{[38]}$ which may signal existence of a physiological limit for the human height.

\subsection{Patterns of becoming overweight}

The age of adiposity rebound is between 5 and 7 years, normally, as previously noted. ${ }^{[14]}$ Before then, BMI reaches a maximum at about one year from birth, and then BMI gradually falls by some $10 \%-15 \%{ }^{[18]}$ before reaching the minimum in the vicinity of 6 years. An early maximum explains an early minimum, and so obesity later in life, and is regarded a result of early birth or imbalanced diet. ${ }^{[14]}$ By the same token, the point of minimum can be hypothesised having bearing on developmental events that follow, and should be regarded a critical age for diet adjustment. Although for each individual the trajectory in the Age - BMI space is unique, populationwide the trajectories have many features in common, and this is reflected in shapes of boundary lines separating the weight zones in Figure 1. The generalised trajectories are different from the boundary lines, although both curve families look alike near the outset due to strong physiological undercurrents. ${ }^{[14,18]}$ Nonetheless, the boundary line changes of direction surely reflect changes in the organism tissue development priorities, which in turn dictates requirements to the diet. Since the boundaries are similar in shape, it is convenient to exemplify one of them, say the overweight boundary. In one study, by analysing a sizable array of longitudinal data through adolescence and young adulthood, it was possible to isolate patterns which led participants to becoming overweight or obese. ${ }^{[40]}$ These patterns translate to certain critical moments in the organism development. Focusing on overweight patterns in males, one such moment is at about 12 years of age (144) months, although the determination of this point is vague due to limited cover of childhood in this analysis. Also, the point has a wide range. Consulting Figure 1, it is not difficult to make a connection of this critical age with the inflection point in the overweight boundary shape. This point certainly marks the transition to adolescence. A poor metabolic control during puberty due to the hormonal changes, affecting also the motivation, exacerbate pre-existing health risks, including obesity. ${ }^{[5]}$ Another critical moment was found in the adolescent range, in the vicinity of 16 years (192 months), which should be the flexion point in the overweight boundary as BMI prepares to level out (see Figure 1). Perhaps this moment is interim. It may be associated with behavioural changes, embracing an adult, more 
sedentary lifestyle. However, the reduced growth not accompanied by appropriate changes to the diet is certainly "indefensible". More interestingly, the total cholesterol reaches a minimum short of 17 years of age. ${ }^{[3]}$ Yet another identified critical age was 19.5 years, which is clearly the beginning of adulthood and can be equally explained. Critical moments identified in the young adulthood range were 22 years and 26 years; they may have a socio-economic meaning. The first was ascribed to the post-college events/stress, and the second to the circumstances surrounding family formation. Other patterns identified do not apply to a particular age and perhaps can be assumed to be a result of presence of negative or positive genetic factors acting throughout life, so that probability of becoming overweight is either negligible or increasing consistently. In females the situation is similar. However, with regards to becoming overweight, the positive genetic factors in females become less and less influential after reaching 21 years of age, which must be the effect of birth giving. While all these patterns appear to be singular, or were indeed "isolated" from the data, clearly the nutritional/behavioural past miscalculations/restrictions can add up, making the weight control more and more difficult.

\section{Conclusion}

In this study, gender-independent, age-dependent BMI levels for children five years of age or older and adolescents, col- lectively juniors, linked to the adult unisex levels at twenty years, were worked out from WHO z-score-based, genderspecific definitions. More precisely, the overweight and the obesity threshold trajectories in the Age - BMI space were piece-wise-linear approximated by pooling male and female data, and conditioned to pass through BMI of 25 and $30 \mathrm{~kg} / \mathrm{m}^{2}$ at twenty years of age, respectively. Using data from NHANES, it was shown that for the noted age range a linearity of high degree exists between WCHR, BMI and Age. A transformation from Age and BMI to WCHR was evaluated, accordingly, and applied to the approximated BMI overweight and obese levels at specified ages. A piece-wise-linear approximation of WCHR age-dependent, BMI-equivalent thresholds, suitable for the junior contingent of population regardless of gender, was thus produced. While WCHR levels change non-monotonically with age for all categories, for the curve representing the overweight threshold this fluctuation is minimal, and effectively the same WCHR level of $47 \%$ applies throughout the junior range. This level is similar to previously independently reported ones. However, all adolescent WCHR category boundaries are rather same-level. So, for this contingent only, the overweight threshold by WCHR can be set at $47.5 \%$ and the first obesity threshold at $54.5 \%$, with all others derived therefrom. A high adherence between resulting BMI and WCHR obesity classifications was demonstrated.

\section{REFERENCES}

[1] Sanders T, Feng X, Fahey PP, et al. Green space and child weight status: does outcome measurement matter? Evidence from an Australian longitudinal study. Journal of Obesity. 2015; 2015 (4): 1-8 PMid:26421185. https://doi.org/10.1155/2015/194838

[2] Short KR, Blackett PR, Gardner AW, et al. Vascular health in children and adolescents: Effects of obesity and diabetes. Vascular Health and Risk Management. 2009; 5: 973-90. PMid:19997578.

[3] Jolliffe CJ, Janssen I. Vascular risks and management of obesity in children and adolescents. Vascular Health and Risk Management. 2006; 2(2): 171-87. https://doi.org/10.2147/vhrm.2006.2. 2.171

[4] Ellis D, Yosuke M. Primary hypertension and special aspects of hypertension in older children and adolescents. Adolescent Health Medicine \& Therapeutics. 2011; 2: 45-62. PMid:24600275. https: //doi.org/10.2147/AHMT.S11715

[5] Moore DJ, Gregory JM, Kumah-Crystal YA, et al. Mitigating microand macro-vascular complications of diabetes beginning in adolescence. Vascular Health and Risk Management. 2009; 5: 1015-31. PMid:19997571.

[6] York C. Heavy childhood television use persists into young adulthood and is associated with increased BMI. Obesity. 2016; 24: 924-8. PMid:27028284. https://doi.org/10.1002/oby.21453

[7] Pitt E, Kendall E, Hills AP, et al. Listening to the experts: is there a place for food taxation in the fight against obesity in early childhood?
BMC Obesity. 2014; 1: (15).

[8] Burns RD, Brusseau TA, Fang Y, et al. Establishing waist-to-height ratio standards from criterion-referenced BMI using ROC curves in low-income children. Journal of Obesity. 2016: 2740538. https : //doi.org/10.1155/2016/2740538

[9] Bibbins-Domingo K, Coxson P, Pletcher MJ, et al. Adolescent overweight and future adult coronary heart disease. New England Journal of Medicine. 2007; 357(23): 2371-9. PMid:18057339. https: //doi.org/10.1056/NEJMsa073166

[10] Ng M, Fleming T, Robinson M, et al. Global, regional, and national prevalence of overweight and obesity in children and adults during 1980-2013: a systematic analysis for the Global Burden of Disease Study 2013. Lancet. 2014; 384: 766-81. https ://doi .org/10.1 016/S0140-6736(14)60460-8

[11] Zhao J, Grant SFA. Genetics of Childhood Obesity. Journal of Obesity. 2011: 845148. PMid:21773009. https://doi.org/10.115 $5 / 2011 / 845148$

[12] Stirrat LI, Reynolds RM. Effects of maternal obesity on early and long-term outcomes for offspring. Research and Reports in Neonatology. 2014; 4: 43-53.

[13] Prendergast AJ, Humphrey JH. The stunting syndrome in developing countries. Paediatrics and International Child Health. 2014; 34(4): 250-65. PMid:25310000. https ://doi . org/10.1179/20469055 $14 \mathrm{Y} .0000000158$ 
[14] Rolland-Cachera MF, Deheeger M, Maillot M, et al. Early adiposity rebound: causes and consequences for obesity in children and adults. International Journal of Obesity. 2006; 30: S11-7. PMid:17133230. https://doi.org/10.1038/sj.ijo.0803514

[15] Frommer M, Byrne S, Caterson I, et al. Clinical practice guidelines for the management of overweight and obesity in adults, adolescents and children in Australia. National Health and Medical Research Council (NHMRC) of Australia; 2013.

[16] Komaroff M. For researchers on obesity: historical review of extra body weight definitions. Journal of Obesity. 2016: 2460285. https://doi.org/10.1155/2016/2460285

[17] Flegal KM, Kit BK, Orpana H, et al. Association of all-cause mortality with overweight and obesity using standard body mass index categories: A systematic review and meta-analysis. Journal of American Medical Association (JAMA). 2013; 309: 71-82. PMid:23280227. https://doi.org/10.1001/jama.2012.113905

[18] Cole TJ, Bellizzi MC, Flegal KM, et al. Establishing a standard definition for child overweight and obesity worldwide: international survey. British Medical Journal (BMJ). 2000; 320: 1240. https://doi.org/10.1136/bmj.320.7244.1240

[19] World Health Organisation (WHO) growth charts. Available from: http://cdc.gov/growthref/en/

[20] Centers for Disease Control (CDC) growth charts. Available from: http://cdc.gov/growthcharts

[21] Nambiar S, Hughes I, Davies PSW. Developing waist-to-height ratio cut-offs to define overweight and obesity in children and adolescents. Public Health Nutrition. 2010; 13(10): 1566-74. PMid:20100388. https://doi.org/10.1017/S1368980009993053

[22] Kline RB. Principles and practice of structural equation modelling; 3-rd ed. 2011. Guilford.

[23] Schult OWB, Feinendegen LE, Zaum S, et al. Applications of BMI or BSI: differences and revisions according to age and height. Journal of Obesity. 2010: 647163. PMid:20975773. https ://doi.org/10 $.1155 / 2010 / 647163$

[24] Savva SC, Lamnisos D, Kafatos AG. Predicting cardiometabolic risk: waist-to-height ratio or BMI - a meta-analysis. Diabetes, Metabolic Syndrome and Obesity: Targets and Therapy. 2013; 6: 40319. PMid:24179379. https://doi .org/10.2147/DMSO.S34220

[25] Ashwell M. Charts based on body mass index and waist-to-height ratio to assess the health risks of obesity: A review. Open Obesity Journal. 2011; 3: 78-84. https ://doi .org/10.2174/18768237 01103010078

[26] National health and nutrition examination surveys. Available from: http://cdc.gov/nchs/nhanes/

[27] Yatsko A. Indexing adult obesity by waist-to-height and weight-toheight ratios. Journal of Biomedical Engineering and Informatics. 2017; 3(2): 20-35. https://doi.org/10.5430/jbei.v3n2p20
[28] Steckel RH. Heights and human welfare: recent developments and new directions. Explorations in Economic History. 2009; 46(1): 1-23. https://doi.org/10.1016/j. eeh.2008.12.001

[29] Plurphanswat N, Rodu B. The association of smoking and demographic characteristics on body mass index and obesity among adults in the U.S., 1999-2012. BMC Obesity. 2014; 1: (18).

[30] Samsell L, Regier M, Walton C, et al. Importance of android/gynoid fat ratio in predicting metabolic and cardiovascular disease risk in normal weight as well as overweight and obese children. Journal of Obesity. 2014: 846578. PMid:25302115. https://doi.org/10.1 155/2014/846578

[31] Rodea-Montero ER, Evia-Viscarra ML, Apolinar-Jiménez E. Waistto-height ratio is a better anthropometric index than waist circumference and BMI in predicting metabolic syndrome among obese Mexican adolescents. International Journal of Endocrinology 2014: 195407. PMid:25574166. https ://doi .org/10.1155/20 $14 / 195407$

[32] Kuba VM, Leone C, Damiani D. Is waist-to-height ratio a useful indicator of cardio-metabolic risk in 6-10-year-old children? BMC Pediatrics. 2013; 13: 91. https ://doi .org/10.1186/1471-243 1-13-91

[33] Moreira C, Santos R, Vale S, et al. Ability of different measures of adiposity to identify high metabolic risk in adolescents. Journal of Obesity. 2011: 578106. PMid:21792387. https ://doi .org/10.1 155/2011/578106

[34] Matsha TE, Kengne AP, Yako YY, et al. Optimal waist-to-height ratio values for cardiometabolic risk screening in an ethnically diverse sample of South African urban and rural school boys and girls. PLoS ONE. 2013; 8(8): (e71133).

[35] Yan W, Bingxian H, Hua Y, et al. Waist-to-height ratio is an accurate and easier index for evaluating obesity in children and adolescents. Obesity. 2007; 15(3): 748-52. PMid:17372326. https: //doi.org/10.1038/oby. 2007.601

[36] Fitnessgram project. Available from: http://www. cooperinstit ute.org/fitnessgram

[37] Garnett SP, Baur LA, Cowell CT. Waist-to-height ratio: a simple option for determining excess central adiposity in young people. International Journal of Obesity. 2008; 32(6): 1028-30. PMid:18414423. https://doi.org/10.1038/ijo.2008.51

[38] Perkins JM, Subramanian SV, Smith GD, et al. Adult height, nutrition, and population health. Nutrition Reviews. 2016; 74(3): 149-65. PMid:26928678. https://doi.org/10.1093/nutrit/nuv105

[39] Schwekendiek D, Jun SH. From the poorest to the tallest in East-Asia: the secular trend in height of South Koreans. Korea Journal. 2010; 50: $151-75$.

[40] Chen X, Brogan K. Developmental trajectories of overweight and obesity of US youth through the life course of adolescence to young adulthood. Adolescent Health, Medicine and Therapeutics. 2012; 3: 33-42. PMid:24600285. https://doi.org/10.2147/AHMT .S30178 